\title{
Inconstitucionalidade das leis
}

\section{G. de Almeida Moura}

O problema da inconstitucionalidade das leis decorre da teoria das Constituições rígidas. Constituição rígida é aquela, cuja reforma, ou emenda, depende de processo especial, por ela mesma previsto, e, em regra, mais complexo que o das leis ordinárias. Para isso, deve o pacto fundamental traduzir-se em um texto escrito e solene.

As Constituições consuetudinárias ou não escritas são, por natureza, flexíveis. Formadas de monumentos legislativos esparsos, ou deles e de usos e costumes consagrados através de numerosos precedentes, nada impede que se lhes adicionem outras leis, e se reconheça o império de novos costumes, não derrogando os anteriores, mas com eles coexistindo, em um regime de dificultosa apreensão. Aí, nem se pode falar em processo de emenda, ou de reforma da Constituição, porque só se reforma, ou se emenda aquilo que é conhecido e traça aos representantes populares os limites dentro dos quais podem legislar.

Filosoficamente, não ha diferença entre Constituição e lei ordinária. A Constituição é apenas uma lei maior, de conteúdo mais amplo e de mais vasto alcance. Eis porque passou a ser preferentemente escrita, na suposição de que mais facilmente se imporia à obediência geral e adquiriria maior estabilidade.

Se, no regime das Constituições costumeiras, o Parlamento legisla soberanamente, no das escritas se prende ao texto constitucional. Se o não fizer, transcende das regras de autorização a que está sujeito, exatamente como o mandatário que, na esfera civil, vai além das faculdades que lhe 
foram outorgadas. Não queremos com isso equiparar um ao outro os dois mandatos, o de Direito Privado e o chamado mandato político, o qual, para nós, não existe, juridicamente falando. No entanto, assim como o mandante não responde pelos excessos do mandatário, assim tambem não tem valor a deliberação legislativa (ou o ato administrativo, de qualquer dos três Poderes), que contrariar dispositivo da Lei Básica, que é certa, conhecida, e se dirige imperativamente a todos, como manifestação suprema do Estado em nome do qual se exercem as funções governamentais.

Inconstitucional é, pois, a lei contrária a disposição da Constituição. Em boa hermenêutica, deve o julgador ser tardo em decretar a inconstitucionalidade, só o fazendo, quando for evidente, e não resistir a nenhum dos processos consagrados na interpretação do Direito Público. E' ainda uma homenagem ao princípio da inviolabilidade da Carta Magna, a presunção de que permite se tomem todas as providências condizentes com a manutenção e o desenvolvimento da ordem jurídica e social.

O problema da inconstitucionalidade das leis tem estado em foco no Brasil, terra de Constituições escritas.

A Constituição do Império apresentava, no entanto, uma anomalia que convem examinar. Rezava o seu art. 178: “ $E$ ' só constitucional o que diz respeito aos limites e atribuições respectivas dos poderes políticos e aos direitos políticos e individuais dos cidadãos: tudo o que não é constitucional pode ser alterado, sem as formalidades referidas, pelas legislaturas ordinárias". A consequência é que ilustres comentadores, como Pimenta Bueno (1) e Rodrigues de SouzA (2) não vacilaram em reduzir a maior parte da Constituição a uma lei ordinária, desde que não podia conside-

(1) Pimenta Bueno, Dr. José Antonio-, Direito Público Brasileiro e Análise da Constituição do Império, Rio de Janeiro. 1857 , p. 489.

(2) Rodrigues de Souza, Desembargador Joaquim -, Análise e comentário da Constituiçâo Politica do Império do Brasil, São Luiz do Maranhão, 1870, vol. II, p. 447. 
rar-se "Constituição" o que não fosse "constitucional". O equívoco era manifesto. O que a Lei Suprema devia ter dito (e não o disse, por falta, na época, de sistematização do Direito Público), é que a Constituição, embora escrita, era rígida em parte e em parte flexivel. Rígida quanto aos alicerces do regime constitucional (separação dos Poderes, representação, direitos e garantias individuais), era, no demais, flexivel, isto é, reformavel por via ordinária. Tudo, porém, era "Constituição". Tudo, "constitucional".

Esse art. 178 foi traduzido, quasi literalmente, do projeto que Constant redigira para a sua Pátria: "Tout ce qui ne tient pas aux limites et aux attributions respectives des pouvoirs, aux droits politiques, et aux droits individuels, ne fait pas partie de la constitution, mais peut être modifié par le concours du roi et des deux chambres" (3). O publicista francês observou que se havia inspirado na organização constitucional da Inglaterra, que é modelo de flexibilidade; fizera-o, no entanto, não por esse motivo, mas por lhe parecer que a Constituição não devia vir pejada de matérias que lhe não pertencem. Assim, pelo renome do grande francês, a sua proposta, tecnicamente defeituosa, e avessa ao constitucionalismo nascido da Revolução, foi acolhida logo depois, e sem maior exame, pelo nascente Império brasileiro.

Não censuremos os eminentes conselheiros de Estado, autores da Carta de 1824, nem a Constant. Ainda no tempo de Rossi, o primeiro que o lecionou em França, de 1835 a 1845, o Direito Constitucional não passava de uma espécie de História Política; a era da escola técnico-jurídica, de Gerber, Laband, Jellinek, Palma, Orlando e seus discípulos, ainda estava por despontar.

Com a Constituição de 1891, o problema da inconstitucionalidade das leis e atos se nos apresentou em toda extensão, conformando-se com a doutrina e a jurisprudência

(3) Constant, Benjamin de - , Collection complète des ouvrages de -, Paris, 1818, vol. I, p. 158. 
norte-americanas. Assim, firmou-se, entre nós, a competência do Judiciário para conhecer da arguição de inconstitucionalidade. A lição de Rú Barbosa (4) triunfou in totum, tanto que, com a Constituição social-democrática de 1934, rígida como a de 91, mas de conteúdo amplificado. prosseguiu o Judiciário na missão de dizer, inapelavelmente, o que era, e o que não era constitucional. A novidade da Constituição de 34 consistiu, quando muito, na atribuição em boa hora conferida ao Senado (art. $90 \mathrm{n}$. IV), de suspender a execução, no todo ou em parte, de qualquer lei ou ato, deliberação ou regulamento, que houvessem sido declarados inconstitucionais pelo Poder Judiciário. Foi um meio termo entre a doutrina norte-americana e, entre outras, a da Constituição Francesa de 1852 (5). Pelo art. 25 desta, o Senado era "o guardião do pacto fundamental e das liberdades públicas". No Brasil, o guardião era o Judiciário. O Senado, como Poder Coordenador, imprimia, no entanto, validade geral a decisões que, por provirem do Judiciário, só vigoravam entre as partes.

Em face da Constituição de 1937, é possivel que alguem negue a existência do problema, argumentando que, mormente agora, nesta fase de transição, durante a qual o Presidente da República detém a plenitude do poder de legislar, em virtude do art. 180 da Constituição, tudo é constitucional, ou que nada é constitucional, o que vem a dar na mesma.

Não iremos, por desnecessária, renovar aquí a discussão sobre se pode, ou não, haver um Estado que não seja constitucional. Estado quer dizer organização jurídica. Por mais rudimentar que esta seja, está ai a sua Constituição. Já o sabia o velho Rossi (6), e é o que, em nossos dias, torna

(4) Barbosa, Rui -, Os atos inconstitucionais do Congresso $e$ do Executivo ante a Justiça Federal, Rio, 1893.

(5) Cf. Laboulaye, Edouard -, L'Etat et ses limites, suivi d'éssais Politiques, Paris, 1863, p. 242.

(6) Rossi, P. - Cours de Droit Constitutionnel, Paris, 1866, vol. I, p. 6 . 
a ensinar Santr Romano (7). No caso do Brasil, a juridicidade da Constituição de 10 de novembro é indiscutivel: a) pelo reconhecimento tácito, ou expresso, do Estado Novo, por parte das potências estrangeiras; b) pelas modificações politicas e administrativas que pacificamente se introduziram no país, em virtude da Constituição (interventorias, departamentos administrativos etc.); c) pelo prosseguimento da tarefa legislativa; d) pela aplicação regular das novas leis, e pelo acatamento que lhes tem dispensado o Judiciário; e) por não ser novidade, na História, a ratificação plebiscitária de uma Constituição. As divergências, se houver, serão de cunho político, e não interessam a compreensão do factum constitucional.

0 art. 180 da Constituição não confundiu o Legislativo com o Executivo. Atribuiu tão só as respectivas funções ao mesmo órgão, temporariamente, "enquanto não se reunir o Parlamento Nacional". Conquanto a distinção seja teórica, dela decorre importante ensinamento. Não pode o Chefe de Estado "converter em lei a sua vontade específica" (8). É, cientificamente falando, um ditador, mas um ditador adstrito à Constituição. Quer dizer que, quando legisla, não the é permitido ir além do que nela se contém, sob pena de ser a lei inquinada de inconstitucional.

$O$ próprio poder público assim o tem compreendido, desde que, até agora, teve a cautela de publicar leis especiais, que, emendando artigos da Carta, criassem para ele outras tantas fontes de autorização. Essas leis constitucionais são já em número de oito: n. 1, de 16-5-1938, emendando $o$ art. 122 n. 13 ; n. 2 , de 16-5-1938, emendando o art. 177; n. 3, de 18-9-1940, emendando os artigos 23 e 35; n. 4, de 20-9-1940, emendando o art. 20; n. 5, de 10-3-1942, emendando os artigos 122, 166 e 168; n. 6, de 13-5-1942, emendando o art. 143; n. 7, de 1-10-1942, emendando o art. 173; e

(7) Romano, Santi -, Corso di Diritto Costituzionale, Pádua, 4. ${ }^{\text {a }}$ ed., 1933 , p. 10.

(8) Monte Arrais, O Estado Novo e suas diretrizes, Rio, 1938, p. 82 . 
n. 8, de 12-10-1942, esclarecendo os artigos 177 e 182 da Constituição. Sete leis de emenda, propriamente ditas, e uma, a última, que é uma Lei de Interpretação, a valer tambem como lei de emenda, desde que só o poder constituinte é capaz de esclarecer, autenticamente, a vontade do legislador constitucional. A objeção de que o texto da Constituição deve ser permanente, tem valor relativo, nas quadras em que a realidade desafia as mais arrojadas previsões.

As alegações de inconstitucionalidade continuam, pois, a ter cabimento. E é ainda aos tribunais que compete decretá-la, por maioria de votos da totalidade dos juizes respectivos. Não obstante, distanciâmo-nos da prática anterior, com instituir um sistema híbrido, que despojou o Judiciário das galas de intérprete último da Constituição.

Efetivamente, no caso de ser declarada a inconstitucionalidade de uma lei que, a juizo do Presidente da República, seja necessária ao bem-estar do povo, à promoção ou defesa do interesse nacional de alta monta, poderá ele submetê-la novamente à exame do Parlamento; se este a confirmar por dois terços de votos de cada uma das Câmaras, ficará sem efeito a decisão do Tribunal. E' o que dispõe o art. $96 \S$ único da Constituição.

Em teoria, nada mais natural que erigir a representação popular, por provocação do Presidente da República, em juiz derradeiro da questão. Acostumados ao uso do judicial control, estranhámos um pouco o novo sistema. Convenhamos, todavia, em que o assunto é controvertido, na doutrina e na legislação. Na Europa, principalmente depois da guerra de 1914, esteve em foco o tema dos tribunais constitucionais, não se tendo chegado, a respeito dele, a um acôrdo. A prática norte-americana não adquiriu prestígio universal. Carl Schmitr foi mesmo entusiasta do Chefe de Estado, como guarda da Constituição. E é notavel que o eminente escritor haja desenterrado do pó dos arquivos, para elogiá-lo calorosamente, como cousa digna de ser revivida, o pouvoir neutre, intermédiaire ou modérateur, preconizado por Constant e acolhido pela Constituição brasileira de 1824 e 
pela Carta portuguesa de 1826 (9). Que muito é, portanto, que o Brasil haja instituido uma guarda constitucional tríplice, por parte do Judiciário, do Executivo e do Legislativo? (10).

O decreto-lei mais importante, fundado nesse assento constitucional, foi o de n. 1.564, de 5 de setembro de 1939, confirmando os textos de lei, decretados pela União, que sujeitaram a imposto de renda os vencimentos pagos pelos cofres públicos estaduais e municipais, e declarando sem efeito as decisões do Supremo Tribunal Federal e de quaisquer outros tribunais e juizes que tivessem decretado a inconstitucionalidade desses mesmos textos. Ainda assim, a 31 de outubro de 1941, o Supremo voltava ao assunto, e, em declaração de voto, sustentava o ministro VALDEMAR FaLcÃo que "não ha inconstitucionalidade nenhuma na cobrança do imposto de renda, sobre os vencimentos de magistrados ou funcionários estaduais, por isso que, não versando tal imposto sobre os "serviços" a que pertencem esses funcionários, mas, sim, sobre o "rendimento" que percebem por sua atividade econômica considerada como tal, não incide esse tributo na proibição constitucional do art. 32 letra $c$ da vigente Constituição, da mesma forma que já não incidia no disposto pelo art. 17, n. X, da Constituição de 1934".

A estranheza não é de ordem doutrinária. Quando o Parlamento estiver reunido, e puder debater as propostas nesse sentido feitas pelo Presidente da República, apreciaremos melhor a interessante novidade. O próprio Judiciário não se deve sentir diminuido por essa limitação constitucional. Contudo, desde que se não imagina a sua existência, a não ser em ambiente de majestoso respeito, é bem de ver que, por motivos evidentes, aconselha a prudência o mais exemplar comedimento, na cassação legislativa das suas decisões.

(9) Schmiтt, Carl -, Der Hüter der Verfassung, Berlim, 1931.

(10) Cfr. Estelita Lins, Augusto E. -, A Nova Constituição dos Estados Unidos do Brasil, Rio, 1938, págs. 13 e segs. 
Feita dessarte a conciliação entre o passado e o presente, entre a doutrina e a prática, resta um ponto a examinar.

Se a nossa Constituição é escrita, e, pelo menos à primeira vista, rígida, desde que as suas emendas, modificações ou reformas hão de se nortear pelo processo do art. 174 e parágrafos, não se nega, em análise mais percuciente, que é igualmente flexivel, ex vi da faculdade do art. 96 $\S$ único. De fato: qual a posição que ocupam, em nosso arcabouço jurídico, as leis declaradas inconstitucionais pelo Judiciário, mas revigoradas, agora pelo Presidente da República, como substituto do Parlamento, e, mais tarde, por este mesmo? E' claro que a de leis adicionais à Constituição, sempre reformaveis, porém, pela via ordinária. E' o que caracteriza as Constituições flexíveis. A Carta de $\mathbf{1 0}$ de novembro segue, dessarte, um sistema mixto, e dela se pode dizer que é, a um tempo, rígida e flexivel. As Constituições flexíveis, como as da Inglaterra e a da Hungria, se caracterizam mais pelos costumes, e pelos precedentes, que pelos textos expressos. A nossa Constituição, que é formada da Carta de 10 de novembro, das leis constitucionais de emenda e das leis ordinárias revalidadas, será sempre escrita. E' assim que o Direito Público se vai transformando diante dos nossos olhos. E é assim que os homens de boa vontade têm de estar sempre prontos a rever as cousas aprendidas, mesmo aquelas que lhes pareciam definitivamente assentadas e de longuíssima duração. A verdade inteira é que, à margem do diploma de 10 de novembro, divisa-se, como que em um mundo a sair de uma nebulosa, a estruturação de uma nova ordem, que pode não ser tão esquemática como as que se descrevem nos velhos compêndios, mas que, sem dúvida, é mais realista, mais consentânea com o deslocamento, em favor do Executivo, do centro de gravitação dos poderes políticos. 